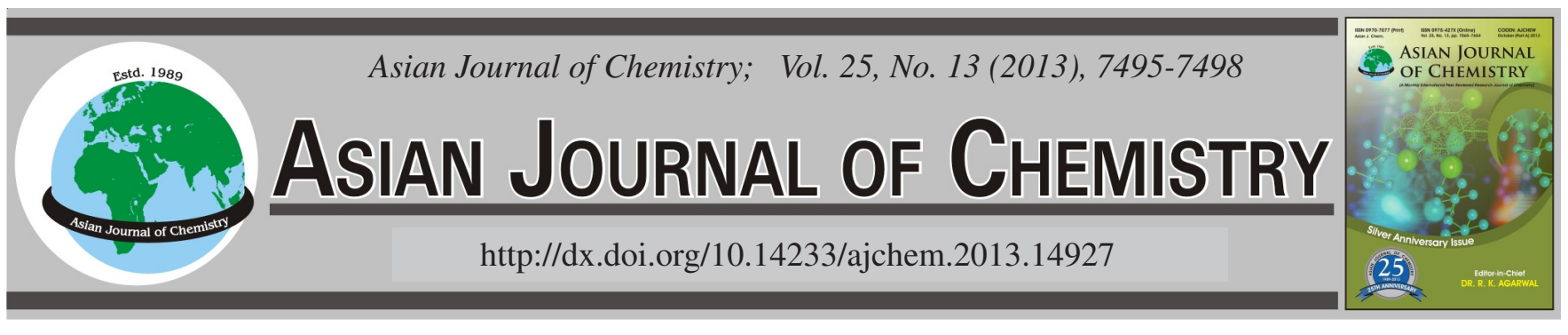

\title{
Investigation of the Effects of Sewage Sludge Addition into Solid Waste Digestion and Leachate Characteristics
}

\author{
O.N. AgDAG ${ }^{1, *}$ and D.T. SpOnZA ${ }^{2, *}$
}

\begin{abstract}
${ }^{1}$ Department of Environmental Engineering, Faculty of Engineering, Pamukkale University, Kinikli Campus, 20070 Denizli, Turkey ${ }^{2}$ Department of Environmental Engineering, Faculty of Engineering, Dokuz Eylül University, Buca Kaynaklar Campus, Izmir, Turkey
\end{abstract}

*Corresponding author: Fax: +90 258 2963262; Tel: +90 258 2963171; E-mail: o.agdag@deu.edu.tr; oagdag@pau.edu.tr

\begin{abstract}
In this study, the effects co-disposal of sewage sludge with organic fraction of municipal solid wastes (OFMSW) were investigated in three simulated landfilling anaerobic bioreactors. One of them was only loaded with OFMSW (control reactor); the second and third reactors were loaded with sewage sludge and OFMSW at different weight ratio of the OFMSW to sewage sludge in order to compare the effects of co-disposal of sewage sludge with the solid wastes. After 61 days of anaerobic incubation, it was observed that the $\mathrm{pH}$, COD, VFA concentrations in the leachate samples of the sewage sludge added reactors (especially run 2) were better than the control reactor. It was observed that the sewage sludge addition significantly increased the methane percentage in the anaerobic simulated reactor.
\end{abstract}

Key Words: Bioreactor, Co-disposal, Municipal solid waste, Sewage sludge.

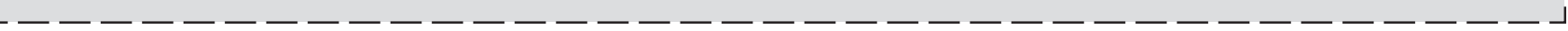

\section{INTRODUCTION}

Anaerobic co-digestion of different kinds of waste sources is a widely applied process that improves digestibility and biogas production by synergistic and complementary effects, which offset the lack of nutrients and dilute harmful substances ${ }^{1}$. The benefits of the co-digestion include: dilution of potential toxic compounds, improved balance of nutrients, synergistic effect of microorganisms, increased load of biodegradable organic matter and better biogas yield. Additional advantages include hygienic stabilization and increased digestion rate ${ }^{2}$.

Sosnowski et al. ${ }^{3}$ presented the results of investigation of methane fermentation of sewage sludge and organic fraction of municipal solid wastes (OFMSW) as well as co-fermentation of both substrates. The results of the study showed that anaerobic co-digestion of sewage sludge and OFMSW seems to be an attractive method for environmental protection and energy savings. Similarly, in the study realized by Zhu et $a l .{ }^{4}$ food waste and sewage sludge was degraded using a respirometric cultivation system. The result of the study showed that hydrogen production potential was enhanced as compared with the individual wastes. In addition, Valencia et al. ${ }^{5}$ found that co-disposal of septic tank sludge has a positive effect on the municipal solid waste stabilization process.

The purpose of this research is to evaluate the effects of co-digestion of sewage sludge with municipal solid waste on the COD removal, VFA accumulation and $\mathrm{pH}$ variation in leachate samples and methane gas productions in laboratory scale simulated anaerobic landfilling reactors through the degradation of OFMSW.

\section{EXPERIMENTAL}

Lab-scale simulated landfill bioreactors: Stainless-steel bioreactors having $10 \mathrm{~cm}$ of diameter and $30 \mathrm{~cm}$ of height were constructed to carry out the study. Schematic configuration of the reactors is shown in Fig. 1. Anaerobic bioreactors were operated in batch mode. Leachate was collected at the bottom of the solid waste reactor and effluent was recycled to the top of the reactor with a peristaltic pump.

Operating protocol for simulated anaerobic landfill bioreactors: All reactors were loaded with solid waste having different operational mode. The first reactor (control reactor) contained only OFMSW (no sewage sludge addition); the second reactor (Run 1) was operated for co-fermentation of sewage sludge and OFMSW. Weight ratio of the OFMSW to sewage sludge was 3:1 (dry solid basis). The third reactor (Run 2) was conducted as a co-fermentation of sewage sludge and OFMSW. Weight ratio of the OFMSW to sewage sludge was 1:3 (dry solid basis). Table-1 shows operating protocol for all reactors.

Analytical procedure: Organic matter, water content, carbon (C) in OFMSW samples and COD concentrations in leachate were detected by using closed reflux colorimetric 


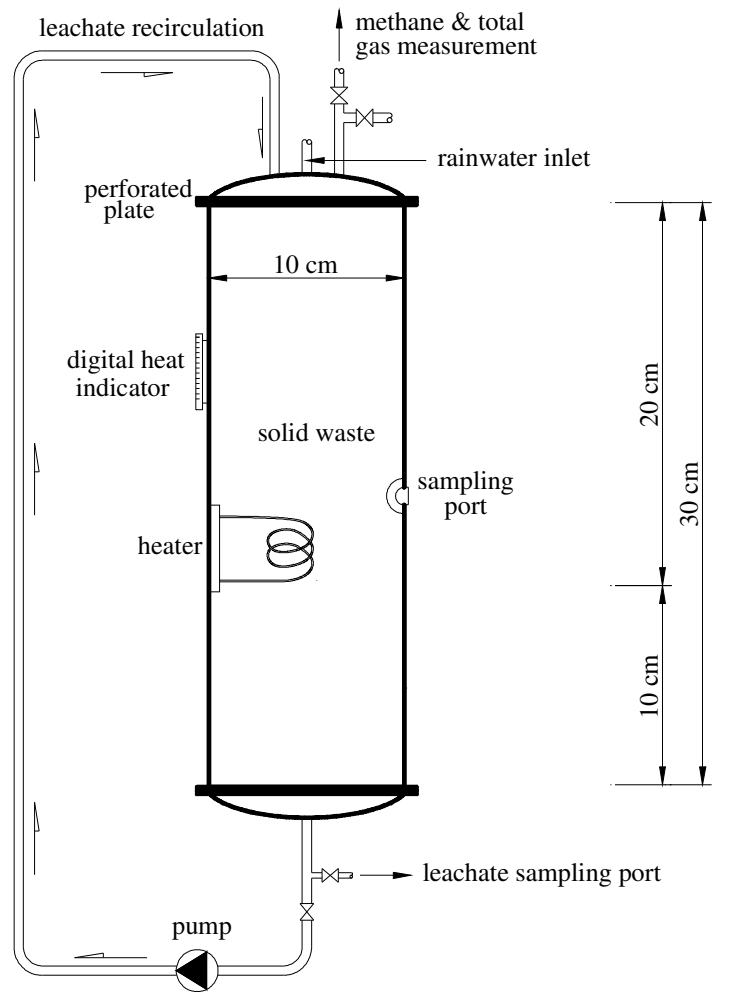

Fig. 1. Schematic configuration of lab-scale anaerobic simulated bioreactor

\begin{tabular}{lccc}
\multicolumn{4}{c}{ TABLE-1 } \\
OPERATING PROTOCOL FOR \\
\multicolumn{4}{c}{ SIMULATED LANDFILL BIOREACTORS } \\
\hline & Control reactor & Run 1 & Run 2 \\
\hline Quantity of waste (g) & 1000 & 1000 & 1000 \\
Weight ratio & No sewage sludge & $3: 1$ & $1: 3$ \\
Water content (\%) & 90 & 88 & 87 \\
Organic matter & 93 & 92 & 80 \\
C (\%) & 52 & 51 & 44 \\
Operation time (day) & 61 & 61 & 61 \\
\hline
\end{tabular}

method following the standard methods ${ }^{6}$. $\mathrm{BOD}_{5}$ was measured using the WTW Oxi Top IS 12 system. Total organic compound was determined with DOHRMANN DC-190 Model high-temperature TOC analyzer. The $\mathrm{pH}$ was determined immediately after sampling using a pH meter, type NEL pH 890. Total volatile fatty acid (TVFA) concentrations in the leachate samples were measured using Anderson-Yang ${ }^{7}$. Gas productions were measured by liquid displacement method. Total gas was measured by passing it through a liquid containing $2 \%(\mathrm{v} / \mathrm{v}) \mathrm{H}_{2} \mathrm{SO}_{4}$ and $10 \%(\mathrm{w} / \mathrm{v}) \mathrm{NaCl}^{8}$. Methane gas was detected using a liquid solution containing $3 \% \mathrm{NaOH}(\mathrm{w} / \mathrm{v})^{9}$. Methane percentage was monitored with a digital methane meter (Drager Pac Ex).

\section{RESULTS AND DISCUSSION}

COD variations in leachate produced from the anaerobic solid waste reactors: COD was monitored as an indicator parameter of leachate organic strength. Fig. 2 shows the daily variation of COD concentrations in leachate for the control, run 1 and run 2 reactors. The initial COD concentration in leachate samples collected from the control, run 1 and run 2 reactors were 26230, 25855 and $17986 \mathrm{mg} / \mathrm{L}$, respectively. The initial COD value of the control reactor was higher than

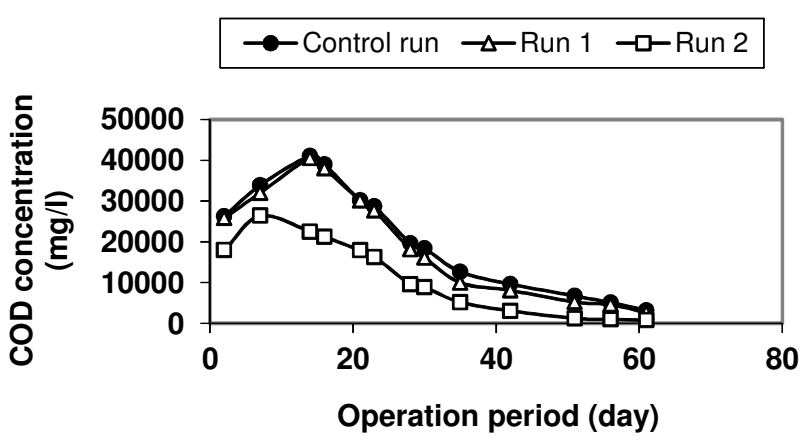

Fig. 2. Daily variation of COD concentrations in leachate for the control, run 1 and run 2

the others because of its high organic matter content. The highest COD value was measured in control reactor among the three reactors during the operation period. Bae et al. ${ }^{10}$ showed that COD concentration in high sewage sludge containing reactor was lower than low sewage sludge containing reactor. The decrease in leachate COD concentration in sewage sludge added reactor can be explained by the rapid conversion of hydrolysis product to methane via methanogens. The result of this study showed that co-digestion of OFMSW with sewage sludge has a relatively positive effect in the decreasing of COD concentrations in simulated anaerobic landfilling bioreactors.

VFA variations in leachate produced from the anaerobic solid waste reactors: Fig. 3 shows the daily variation of VFA concentrations. The concentration of VFAs in leachate produced from the all reactors exhibit similar data with COD levels. The highest VFA value occurred in control reactor among the three reactors since contains high organic matter. Organic matter degradation in initial phase of the fermentation caused high VFA concentration. At the end of the study, the final VFA concentrations in leachate samples were 1204, 995 and $705 \mathrm{mg} / \mathrm{L}$ in control, run 1 and run 2 reactors, respectively. The lower VFA concentration was shown in sewage sludge containing reactors. Bae et al..$^{10}$ found that the VFA concentrations in sewage sludge containing reactor was lower than the control reactor.

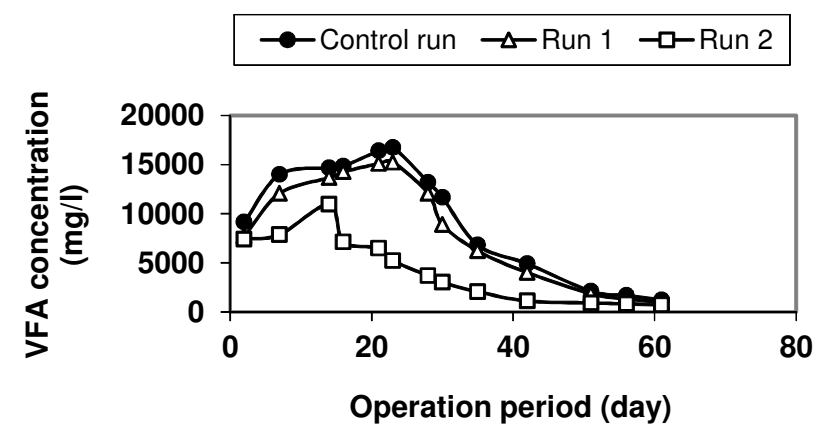

Fig. 3. Daily variation of VFA concentrations in leachate for the control, run 1 and run 2

pH variations in leachate produced from the anaerobic solid waste reactors: The $\mathrm{pH}$ of the leachate samples are in accordance with the concentration of VFA measured in all reactors. The variation of $\mathrm{pH}$ profiles over time is illustrated in Fig. 4. The pH value in run 2 was higher than that run 1 and control reactors during the anaerobic operation period. This study showed that run 2 has an advantage in terms of $\mathrm{pH}$ since 


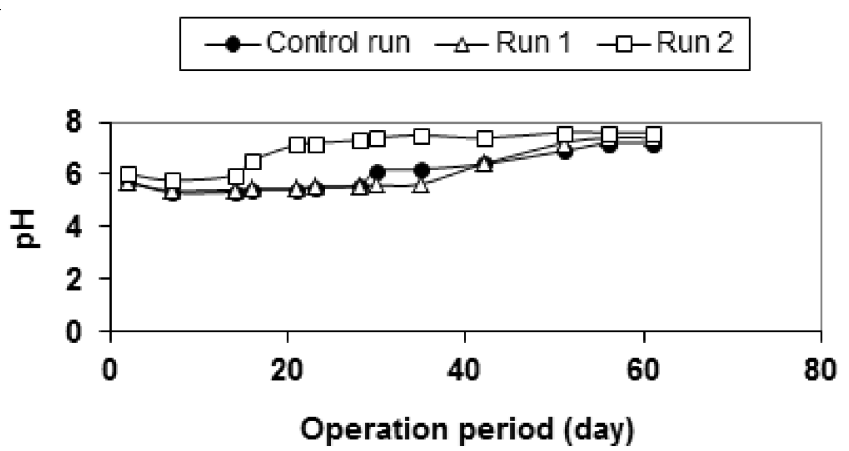

Fig. 4. Daily variation of $\mathrm{pH}$ concentrations in leachate for the control, run 1 and run 2

the $\mathrm{pH}$ levels measured in control, run 1 and run 2 reactors were 7.2, 7.4 and 7.6, respectively, on day 61. Despite the $\mathrm{pH}$ values of the bioreactors were similar at the end of the study, the $\mathrm{pH}$ value of the run 1 and control reactors (particularly in control reactor) were measured approximately 5.5 during the operation period. The low $\mathrm{pH}$ values were attributed to the generation and accumulation of volatile organic acids. Probably in run 1, the seed was not enough to improve the buffer capacity of the system. Similarly in our study, the $\mathrm{pH}$ of the sewage sludge added reactors was found approximately 7.5 similar to the study performed by Warith ${ }^{11}$.

Methane gas productions and percentages in the anaerobic solid waste reactors: Methane gas productions were monitored as an indication of the progression of waste decomposition in the reactors. Quantity of methane and methane percentage in control, run 1 and run 2 reactors were shown in Figs. 5 and 6, respectively. The maximum cumulative methane gas production was recorded as 12.6, 14.9 and $23.7 \mathrm{~L}$ in control, run 1 and run 2 reactors, respectively at the end of 61 days. The reason for the high cumulative methane level in sewage sludge added reactors is high biodegradation rate of organic wastes by microorganisms in these reactors. The highest methane percentages were 58, 60 and $70 \%$ in control, run 1 and run 2 reactors, respectively during the operation period.

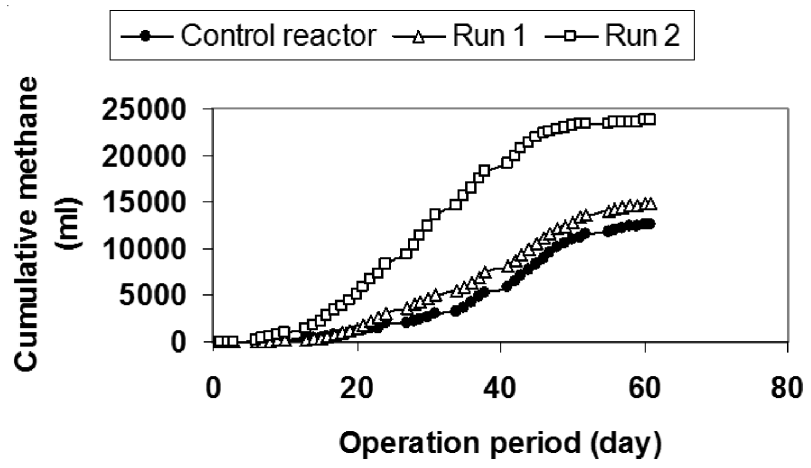

Fig. 5. Variation in cumulative methane gas productions in the control, run 1 and run 2 reactors through 61 days of anaerobic incubation

$\mathrm{BOD}_{5}, \mathrm{BOD}_{5} / \mathrm{COD}$ ratios and $\mathrm{TOC}$ in leachate samples taken from the anaerobic solid waste reactors: In order to determine the proportion of biodegradable organic carbon in the leachate samples it was determined the $\mathrm{BOD}_{5} / \mathrm{COD}$ ratios. Table- 2 shows the computed values of $\mathrm{BOD}_{5}, \mathrm{COD}$ concentrations, $\mathrm{BOD}_{5} / \mathrm{COD}$ ratios and TOC values in the leachate



Fig. 6. Variation in methane percentages in the control, run 1 and run 2 reactor through 61 days of anaerobic incubation

samples of the all reactors studied for days 14, 30 and 56. The highest $\mathrm{BOD}_{5}$ decreases were occurred in reactor containing a municipal solid waste to sewage sludge ratio of 1:3 (run 2). The experimental results indicate that, the addition of sewage sludge significantly increased the $\mathrm{BOD}_{5}$ removals. In the study carried out by Warith ${ }^{11}$, the highest $\mathrm{BOD}_{5}$ value was occurred in the sewage sludge added reactor. Total organic compund give an indication of the amount of organic substrate in the leachate. Total organic compund value of the run 2 reactor was determined as $7850 \mathrm{mg} / \mathrm{L}$ on day 14 . However, it decreased to $254 \mathrm{mg} / \mathrm{L}$, resulted a TOC removal efficiency of $97 \%$ on day 56. This result indicated that, initially, the co-disposing of sewage sludge with OFMSWs were released organic carbon at high concentrations since the mixture of these wastes biodegraded very rapidly.

Comparison of the characteristics of the municipal solid waste in the anaerobic bioreactors: Table- 3 shows that the organic matter reduction in run 2 reactor is the highest level. The percentage of organic matter reduction in control, run 1 and run 2 reactors are 34, 37 and $56 \%$, respectively through 61 days of incubation period. In addition, waste settlement and the reductions in $\mathrm{C}$ percentage and waste quantity in run 2 reactor was found to be at higher level.

\section{Conclusion}

The results of this study showed that co-digestion of sewage sludge and municipal solid wastes has a positive effect on the rate of biological degradation in anaerobic simulated recycled reactors through the degradation of OFMSW. The anaerobic co-digestion of sewage sludge and OFMSW seems to be an attractive method for environmental protection and energy savings. The municipal wastewater treatment plant sludge should be directly co-disposed with solid waste in anaerobic landfilling bioreactor to investigate an alternative method for sewage sludge digestion and disposal. The mixture of sewage sludge with OFMSW could be a richer source of organic materials and hence conducive to effective anaerobic biodegradation. It was aimed to use the anaerobic simulated landfilling bioreactors as anaerobic sludge digesters for more economic sludge digestion and acceleration of waste stabilization to enhance methane gas recovery. Addition of sewage sludge increases the cumulative gas production, indicating the enhancement of solid waste stabilization. This enhancement can be explained by the favorable environment created by the 
TABLE-2

$\mathrm{BOD}_{5}$, COD CONCENTRATIONS, BOD $/$ /COD RATIOS AND TOC VALUES IN THE LEACHATE SAMPLES OF THE BIOREACTORS

\begin{tabular}{|c|c|c|c|c|c|c|c|c|c|}
\hline & \multicolumn{3}{|c|}{ Control reactor } & \multicolumn{3}{|c|}{ Run 1} & \multicolumn{3}{|c|}{ Run 2} \\
\hline & Day 14 & Day 30 & Day 56 & Day 14 & Day 30 & Day 56 & Day 14 & Day 30 & Day 56 \\
\hline $\mathrm{BOD}_{5}(\mathrm{mg} / \mathrm{L})$ & 35005 & 13056 & 1896 & 33596 & 11270 & 1616 & 16874 & 4521 & 237 \\
\hline $\mathrm{COD}(\mathrm{mg} / \mathrm{L})$ & 41067 & 18389 & 5124 & 40478 & 16100 & 4616 & 22481 & 8865 & 988 \\
\hline $\mathrm{BOD}_{5} / \mathrm{COD}$ ratio & 0.85 & 0.71 & 0.37 & 0.83 & 0.70 & 0.35 & 0.75 & 0.51 & 0.24 \\
\hline TOC (mg/L) & 12525 & 7050 & 1668 & 11415 & 5960 & 1110 & 7850 & 3019 & 254 \\
\hline
\end{tabular}

TABLE-3

COMPARISON OF CHARACTERISTICS OF THE SIMULATED ANAEROBIC LANDFILLING MSW REACTORS

\begin{tabular}{|c|c|c|c|c|c|c|}
\hline & \multicolumn{3}{|c|}{ Initial } & \multicolumn{3}{|c|}{ Final } \\
\hline & Control & Run 1 & Run 2 & Control & Run 1 & Run 2 \\
\hline Water content $(\%)$ & 90 & 88 & 87 & 91 & 90 & 90 \\
\hline Org. matter (\%) (in DS) & 93 & 92 & 80 & 61 & 58 & 35 \\
\hline $\mathrm{C} \%$ (in DS) & 52 & 51 & 44.4 & 33.89 & 32.2 & 19.4 \\
\hline Waste height $(\mathrm{cm})$ & 30 & 30 & 30 & 14 & 13 & 10 \\
\hline Waste quantity (g) & 1000 & 1000 & 1000 & 315 & 291 & 119 \\
\hline
\end{tabular}

addition of sewage seed. The addition of sewage sludge increased the bacterial population and increased the concentration of available soluble substrate required by the bacteria together with municipal solid wastes. The utilization of sewage sludge with municipal solid waste, in future, may be create a more suitable environment for the onset of methanogenesis for sludge digestion along with municipal solid waste stabilization.

\section{REFERENCES}

1. D.H. Kim, S.H. Kim, H.W. Kim, M.S. Kim and H.S. Shin, Bioresour. Technol., 102, 8501 (2011).

2. P. Sosnowski, A. Wieczorek and S. Ledakowicz, Adv. Environ. Res., 7, 609 (2003).
3. P. Sosnowski, A. Klepacz-Smolka, K. Kaczorek and S. Ledakowicz, Bioresour. Technol., 99, 5731 (2008).

4. H. Zhu, W. Parker, R. Basnar, A. Proracki, P. Falletta, M. Beland and P. Seto, Int. J. Hydrogen Energy, 33, 3651 (2008).

5. R. Valencia, D. Hamer, J. Komboi, H.J. Lubberding and H.J. Gijzen, J. Environ. Manage., 90, 940 (2009).

6. APPA-AWWA: Standard Methods for the Examination of Water and Wastewater, Washington, DC (1992).

7. G. Anderson and G. Yang, Water Environ. Res., 64, 53 (1992).

8. M.I. Beydilli, S.G. Pavlosathis and W.C. Tinvher, Water Sci. Technol., 38, 225 (1998).

9. E. Razo-Flores, M. Luijton, B.A. Donlon, G. Letting and J.A. Field, Water Sci. Technol., 36, 65 (1997).

10. J.H. Bae, K.W. Cho, B.S. Bum, S.J. Lee and B.H. Yoon, Water Sci. Technol., 38, 159 (1998).

11. M. Warith, Waste Manage., 22, 7 (2002). 